\title{
Predictors of Coronary Atherosclerosis: HSP70, Markers of Oxidative Stress and Endothelial Dysfunction
}

\author{
Julia A. Kotova, PhD*; Anna A. Zuikova, PhD, ScD; Aleksander N Pashkov, PhD, ScD; \\ Natalia V. Strahova, PhD; Olga N. Krasnorutskaya, PhD \\ Voronezh State Medical University named after N.N. Burdenko \\ Voronezh, Russian Federation
}

\begin{abstract}
The aim of this study was to evaluate the role of HSP70, and markers of oxidative stress and endothelial dysfunction, as determinants of the severity of coronary atherosclerosis. The study revealed significant differences between patient groups with and without coronary atherosclerosis in terms of HSP70, superoxide dismutase, total homocysteine (tHcy) and markers of oxidative modification of proteins. Significant correlations between Gensini score, lipid profile parameters and studied markers were determined. The results of multiple linear regression analysis allow us to consider the levels of HSP70, tHcy, LDL-C and ketone derivative of 2.4-dinitrophenylhydrazine as factors associated with the risk of coronary atherosclerosis.(International Journal of Biomedicine. 2019;9(2):97-101.)
\end{abstract}

Key Words: coronary atherosclerosis $\bullet$ heat shock protein $70 \bullet$ superoxide dismutase $\bullet$ homocysteine

\section{Abbreviations}

ADPH, aldehyde derivative of DNPH; CHD, coronary heart disease; CAG, coronary angiography; CA, coronary atherosclerosis; DNPH, 2.4-dinitrophenylhydrazine; ED, endothelial dysfunction; GS, Gensini score; HSPs, Heat shock proteins; HSP70, heat shock protein 70; HDL-C, high-density lipoprotein cholesterol; KDPH, ketone derivative of DNPH; LDL-C, low-density lipoprotein cholesterol; MLRA, multiple linear regression analysis; OS, oxidative stress; OMP, oxidative modification of proteins; ROS, reactive oxygen species; SOD, superoxide dismutase; TC, total cholesterol; TG, triglycerides; tHcy, total homocysteine.

\section{Introduction}

Coronary artery disease (CAD) is the leading cause of death and disability worldwide. ${ }^{(1,2)}$ Atherosclerosis, which is the primary pathophysiologic mechanism for the development of plaque leading to $\mathrm{CAD}$, is a multifactorial and multifaceted process. In this process, fundamental roles for inflammation and OS have been established. ${ }^{(3-6)} \mathrm{In} \mathrm{CHD}$, a decrease in intracellular protection against reactive oxygen species, primarily due to a decrease in the level of SOD - the key enzyme of the antioxidant system-has been demonstrated by a number of researchers. ${ }^{(7)}$ The imbalance between pro-oxidants and

*Corresponding author: Julia A. Kotova, PhD. Voronezh State Medical University n. a. N.N. Burdenko. Voronezh, Russia. E-mail: kotova_u@inbox.ru antioxidants leads to oxidative damage of proteins - an early indicator of the cell damage, ${ }^{(8,9)}$ including the endothelium.In contrast to their inherent harms, ROS also function as signaling molecules, inducing stress tolerance mechanisms. OS can be responsible for the increased expression of HSPs. HSPs have been reported to work together with the antioxidant system to inhibit or neutralize the cellular effects of ROS..$^{(10-12)} \mathrm{OS}$ is one of the most important factors that produce ED. ED contributes to atherogenesis at every phase of atherosclerosis ${ }^{(13)}$ In addition, Hcy is an established biomarker for ED and vascular disease, and is linked to increased OS. ${ }^{(14)}$ Elevated Hcy promotes atherosclerosis through increased OS, impaired endothelial function, and induction of thrombosis. ${ }^{(15)}$

In this regard, the aim of this study was to evaluate the role of HSP70, and markers of OS and ED, as determinants of the severity of CA. 


\section{Materials and Methods}

We examined 354 CHD patients (175 women and 179 men aged between 47 and 75 years, mean age of $61.8 \pm 8.1$ years) who had CA of varying degrees, according to CAG.

All patients underwent the following examinations: assessment of traditional risk factors, physical examination, clinical and biochemical laboratory methods, 12-lead ECG, echocardiography, Holter ECG monitoring, treadmill test, and coronary angiography. Blood samples were obtained in the morning after a $12 \mathrm{~h}$ overnight fast. The levels of total cholesterol (TC), low-density lipoprotein cholesterol (LDL-C), high-density lipoprotein cholesterol (HDL-C), triglycerides (TG) were determined in the blood plasma using "Daytona» analyzer (RANDOX, Ireland).

CAG was performed by the Judkins technique using General Electric Innova 3100 (GE Healthcare, USA).

The severity of CAD was evaluated by the Gensini score (GS). ${ }^{(16)}$ The severity of the disease is expressed as the sum of the scores for individual lesions and the functional importance index of the area of each lesion in the coronary tree. According to the calculated GS, patients were divided into two groups: GS0 - 152 patients with normal coronary artery and GS $>1-202$ patients with mild to severe coronary stenosis. In Group GS0, 53(35\%) patients received statins for more than 6 months before the study, 99(65\%) patients did not receive statins for 6 months before the study. In Group GS $>1,79(39 \%)$ patients received statins for more than 6 months before the study, 123(61\%) patients did not receive statins for 6 months before the study.

The determination of OMP in the blood serum was carried out using the methods by Dubinina et al. ${ }^{(17)}$ The assay is based on the spectrophotometric detection of the reaction between 2.4-dinitrophenylhydrazine (DNPH) with protein carbonyl to form protein hydrazone. The optical density of 2,4-dinitrophenylhydrazones derivates was recorded on an SF-36 spectrophotometer. The optical density of aldehydeand ketone derivatives of a neutral character was recorded at $356 \mathrm{~nm}$ and $370 \mathrm{~nm}$, respectively (ADPHn and KDPHn). The optical density of aldehyde- and ketone derivatives of a basic character was recorded at $430 \mathrm{~nm}$ and $530 \mathrm{~nm}$, respectively (ADPHb and $\mathrm{KDPHb}$ ).

The SOD activity was determined by the spectrophotometric method. The serum level of tHcy was determined by EIA using «Axis-Shield» test kit. Extracellular Hsp70 was measured by ELISA (Elisa Kit for Hsp70, CloudClone Corp.) in blood samples.

Statistical analysis was performed using statistical software package SPSS version 20.0 (SPSS Inc, Chicago, IL). Median values are presented with interquartile (IQ) ranges (IQR; 25th to 75th percentiles). The Mann-Whitney test was used to compare median values. The frequencies of categorical variables were compared using Pearson $\chi 2$. The Spearman correlation coefficient $\left(\mathrm{r}_{\mathrm{s}}\right)$ was used to assess the relationship between variables. Stepwise multiple linear regression analysis (MLRA) was done to determine the variables with independent significant association with the severity of coronary atherosclerosis, and included all variables (biochemical markers and lipid metabolism indicators) with significant relationship with coronary atherosclerosis in univariate analyses $(P<0.05$ after correction for multiple comparisons). Probability values less than 0.05 were considered statistically significant. A probability value of $P<0.05$ was considered statistically significant.

The study was approved by the Voronezh State Medical University Ethics Committee. Written informed consent was obtained from all patients.

\section{Results}

The main characteristics of the patients are presented in Table 1. The patients of the two groups were comparable in age. In Group GS>1, with a predominance of men, an average statistical power was found between the presence of $\mathrm{CA}$, determined by the GS index, and the gender of patients $\left(\chi^{2}=14.174, P=0.0001 ; \varphi=0.459, P=0.0001\right)$. In addition, the statistical relationship between gender and the number of affected vessels was determined: An insignificant lesion was more common in women $(83 \%)$, two-vessel lesions were common in men $(58.7 \%)$ and women $(41.3 \%)$, and the three-vessel or multivessel lesions were predominant in men $(61.6 \%)\left(\chi^{2}=8.116, P=0.017\right)$. The blood levels of TC, LDL-C and HDL-C also differed significantly between the two groups. GS $>1$ patients had higher levels of tHcy and OMP and lower levels of HSP70 and SOD activity (Table 2).

Table 1.

The main characteristics of the patients (Me, IQR / $\left.\mathrm{P}_{25} ; \mathrm{P}_{75} l\right)$

\begin{tabular}{|l|c|c|c|}
\hline \multicolumn{1}{|c|}{ Variable } & GS0 & GS1 & $P$-value \\
\hline Men & 51 & 128 & \\
\hline Women & 101 & 74 & \\
\hline Age, years & $59.1[51 ; 67.5]$ & $60.59[57 ; 65]$ & 0.742 \\
\hline TC, $\mathrm{mmol} / 1$ & $4.54[4.2 ; 3.8]$ & $5.82[5.15 ; 6.8]$ & 0.001 \\
\hline TG, $\mathrm{mmol} / 1$ & $1.2[1.1 ; 1.3]$ & $1.43[1.1 ; 1.57]$ & 0.259 \\
\hline LDL-C, $\mathrm{mmol} / 1$ & $2.44[2.05 ; 2.76]$ & $2.94[2.37 ; 2.94]$ & 0.05 \\
\hline HDL-C, $\mathrm{mmol} / 1$ & $1.19[1.1 ; 1.3]$ & $1.01[0.9 ; 1.1]$ & 0.003 \\
\hline
\end{tabular}

Table 2.

The blood levels of studied markers (Me, IQR $\left.\left./ \mathrm{P}_{25} ; \mathrm{P}_{75}\right]\right)$

\begin{tabular}{|l|c|c|c|}
\hline \multicolumn{1}{|c|}{ Variable } & GS0 & GS1 & $P$-value \\
\hline HSP70, ng/ml & $4.47[4.12 ; 4.98]$ & $3.11[2.63 ; 3.71]$ & 0.000 \\
\hline SOD, $\%$ & $39.10[39.10 ; 43.89]$ & $34.99[32.26 ; 36.14]$ & 0.000 \\
\hline tHcy, $\mu \mathrm{mol} / 1$ & $8.47[8.47 ; 9.97]$ & $11.46[10.36 ; 12.0]$ & 0.000 \\
\hline ADPHn, IU/mg & $21.88[21.54 ; 22.29]$ & $25.9[24.30 ; 27.31]$ & 0.000 \\
\hline KDPHn, IU/mg & $20.32[19.88 ; 20.32]$ & $21.43[20.51 ; 22.74]$ & 0.003 \\
\hline ADPHb, IU/mg & $10.73[10.54 ; 10.88]$ & $11.07[10.67 ; 11.71]$ & 0.075 \\
\hline KDPHb, IU/mg & $2.54[2.34 ; 8.72]$ & $6.87[6.34 ; 8.50]$ & 0.006 \\
\hline
\end{tabular}

A correlation analysis revealed direct correlations between GS and tHcy, indicators of OMP, as well as inverse correlations between GS and SOD activity. In addition, inverse 
correlations were found between HSP70 and TC and LDL-C; SOD activity and TC; ADPHn, KDPHn and HDL-C. Direct correlations were found between HSP70 and SOD activity and HDL-C; ADPHn, KDPHn, ADPHb, KDPHb and TC; ADPHn and TG, LDL-C. We also found significant correlations between the GS and lipid profile parameters (TC $\left[\mathrm{r}_{\mathrm{s}}=0.61\right.$, $P=0.000]$, TG $\left[\mathrm{r}_{\mathrm{s}}=0.27, P=0.04\right]$, LDL-C $[\mathrm{r}=0.45, P=0.001]$, and HDL-C $\left.\left[\mathrm{r}_{\mathrm{s}}=-0.46, P=0.000\right]\right)$.

On the first step of MLRA, the inclusion of HSP70 into the regression model (negative regression coefficient) explained $67 \%$ of the variance of the dependent variable (Table 3). On the second step, with the tHcy inclusion into the model, the relationship between HSP70 level and the presence of coronary atherosclerosis was maintained, and this model explained $73.1 \%$ of the variance of the dependent variable. The third predictor in the model was LDL-C. With the continued contribution of HSP70 and tHcy to the development of coronary atherosclerosis, this model explained 75.3\% of the variance of the dependent variable. On the next step, the input variable was found to be KDPHb, and the model explained $76.7 \%$ of the variance of the dependent variable. At this step, the regression analysis was completed, which confirms the greatest importance of 4 markers in predicting coronary atherosclerosis: HSP70, tHcy, LDL-C, and KDPHb. The forced inclusion of other biochemical markers did not improve the model: The regression coefficients for them, as independent predictors, were insignificant, the standardized regression coefficients were low, the incremental $\mathrm{R}^{2}$ was insignificant, and the partial F-test did not reveal significant differences among the models.

\section{Table 3.}

Results of the multiple linear regression analysis

\begin{tabular}{|c|c|c|c|c|c|c|}
\hline Variable & $\mathrm{B} \pm$ Std. Error & $\beta$ & $P$ & $\mathrm{adR}^{2}$ & $\mathrm{~F}$ & $P$ \\
\hline \multicolumn{4}{|c|}{ Model 1} & 0.670 & 106.632 & 0.000 \\
\hline HSP70 & $-0.851 \pm 0.082$ & -0.822 & 0.000 & & & \\
\hline \multicolumn{4}{|c|}{ Model 2} & 0.731 & 71.785 & 0.000 \\
\hline HSP70 & $-0.524 \pm 0.118$ & -0.506 & 0.000 & & & \\
\hline tHcy & $3.290 \pm 0.926$ & 0.406 & 0.001 & & & \\
\hline \multicolumn{4}{|c|}{ Model 3} & 0.753 & 53.702 & 0.000 \\
\hline HSP70 & $-0.537 \pm 0.114$ & -0.519 & 0.000 & & & \\
\hline tHcy & $2.660 \pm 0.930$ & 0.328 & 0.006 & & & \\
\hline LDL-C & $2.210 \pm 0.962$ & 0.173 & 0.026 & & & \\
\hline \multicolumn{4}{|c|}{ Model 4} & 0.767 & 39.025 & 0.000 \\
\hline HSP70 & $-0.511 \pm 0.019$ & -0.490 & 0.000 & & & \\
\hline tHcy & $2.576 \pm 0.956$ & 0.312 & 0.032 & & & \\
\hline LDL-C & $1.982 \pm 0.908$ & 0.150 & 0.047 & & & \\
\hline $\mathrm{KDPHb}$ & $0.903 \pm 0.254$ & 0.164 & 0.049 & & & \\
\hline
\end{tabular}

Analyzing the ratios of standardized regression coefficients included in the regression analysis, it can be noted that the relative unique prognostic importance of HSP70, as an independent predictor of coronary atherosclerosis, is about -0.5 . That is, when other independent predictors remain unchanged, and the HSP70 level increases by 1 standard deviation, then the severity of coronary atherosclerosis decreases by 0.5 standard deviation. This once again confirms the high importance of HSP70 as a protective factor for coronary atherosclerosis within these regression models.

\section{Discussion}

Identifying patients at early stages of coronary atherosclerosis is still a major problem. In the past two decades, numerous studies have demonstrated the importance of oxidative stress in the development of atherosclerosis. Elevated concentrations of a variety of oxidative stress markers were linked to a more frequent occurrence of cardiac events. ${ }^{(18)}$ The study performed by Y Huo et al. ${ }^{(19)}$ revealed metabolic disturbances in the model of long-term hyperhomocysteinemia together with vascular remodeling. Authors suggested that OS, ED, and decreased PPAR $\gamma$ expression in the vessel wall could be underlying mechanisms. Activation of ROS transduce matrix metalloproteinase, renders eNOS ineffective and promotes endothelial-smooth muscle disconnection/uncoupling by antagonizing PPAR $\gamma .{ }^{(20)}$ Elevated levels of plasma Hcy cause endothelial dysfunction and vascular diseases. ${ }^{(21,22)}$ The importance of homocysteine in vascular function and arteriosclerosis was discovered by demonstration of arteriosclerotic plaques in children with homocystinuria caused by inherited enzymatic deficiencies of cystathionine synthase, methionine synthase, or methylenetetrahydrofolate reductase. ${ }^{(23,24)}$ Nonfasting plasma tHcy levels were independently associated with increased rates of allcause and CVD mortality in the elderly Framingham men and women. ${ }^{(25)}$ The elevated levels of homocysteine and indicators of oxidative stress were also found in our study. At the same time, a significant difference between GS0 and GS $>1$ precisely in ketone derivatives indicates the duration of oxidative stress and the degree of destruction of the protein molecule.

The activation of HSP70 may play a role in protecting the cells against oxidative stress and inflammatory damage. ${ }^{(26)}$ When assessing the level of HSP70, we found a decrease in its level in the presence of coronary atherosclerosis, as well as a high association with GS. The first evidence that high levels of human HSP70 are associated with low CAD risk, probably through its multiple protective effects on a cell's response to stress, was provided by Zhu et al. ${ }^{(27)}$ However, there are conflicting reports that preclude assigning HSP70 a definite role in atherosclerosis at present. Plasma levels of HSP70 have been found to have an inverse ${ }^{(27,28)}$ as well as a direct association ${ }^{29,30)}$ with the severity of atherosclerosis. HSP70 is presently a matter of debate. ${ }^{(31,32)}$ High levels of circulating HSP70 (HSPA1A) are associated with low risk of CAD; ${ }^{(27)}$ they appear in hypertensive subjects with a lesser intima media, thickening after 4 years of follow-up. ${ }^{(33)}$ In the study by E. Dulin, extracellular HSP70 and anti-HSP70 antibody concentrations have been proposed as biomarkers for the progression of atherosclerotic disease. ${ }^{(34)}$ At least 4 studies have demonstrated that the transgenic overexpression of HSP70 in the heart of mice significantly protects against ischemia/reperfusion injury. ${ }^{(35-38)}$ 
Thus, our findings emphasize the significance of the studied markers in the pathogenesis of coronary atherosclerosis and make it possible to use the indicators of HSP70, tHcy, LDL-C and KDPHb in screening the risk for the development of coronary atherosclerosis.

\section{Conclusion}

The study revealed significant differences between groups with and without coronary atherosclerosis in terms of HSP70, superoxide dismutase, tHcy and markers of oxidative modification of proteins (except ADPHb). Significant correlations between Gensini score, lipid profile parameters and studied markers were determined. The results of multiple linear regression analysis allow us to consider the levels of HSP70, total homocysteine, low-density lipoprotein cholesterol and $\mathrm{KDPHb}$ as factors associated with the risk of coronary atherosclerosis.

\section{Competing Interests} interests.

The authors declare that they have no competing

\section{Sources of Funding}

This work was partially supported by the Council on Grants of the President of the Russian Federation for State Support of Young Scientists and Leading Scientific Schools (Grant MK-552.2018.7).

\section{References}

1. Mendis S, Puska P, Norrving B, Organization WH, Federation WH, Organization WS. Global atlas on cardiovascular disease prevention and control. Geneva: World Health Organization; 2011. Available from: http://www.who. int/iris/handle/10665/44701

2. WHO | Cardiovascular diseases (CVDs]. Geneva: World Health Organization; 2017. Available from: http://www.who. int/mediacentre/factsheets/fs317/en/

3. Ragino YuI, Chernyavskij AM, Eremenko NV, Shakhtshnejder EV, Polonskaya YaV, Tsimbal SYu, et al. [Key laboratory diagnostic biomarkers of coronary atherosclerosis]. Kardiologiia. 2011;51(3):42-6. [Article in Russian].

4. Vertkin AL, Topolyanskij AV. [The problem of hyperhomocysteinemia in cardiac patients]. Farmateka. 2007;15:10-14. [Article in Russian].

5. L'vovskaya EI, Sahankova EN. [The ratio of levels of lipid peroxidation and oxidative modification of proteins in students 17-23 years (Kungur)]. Vestnik YUrGU. 2012; 21: 112-116. [Article in Russian].

6. Musthafa QA, Abdul Shukor MF, Ismail NAS, Mohd Ghazi A, Mohd Ali R, M Nor IF, et al. Oxidative status and reduced glutathione levels in premature coronary artery disease and coronary artery disease. Free Radic Res. 2017 Oct;51(910):787-798. doi: 10.1080/10715762.2017.1379602 .

7. Zanozina OV, Brovkova NN, Shcherbatyuk TE. [Oxidized modified proteins in the atherosclerosis genesis at a diabetes mellitus of the 2nd type]. Sovremennye Tehnologii v
Medicine. 2009;2:72-75. [Article in Russian].

8. Bykova AA, Azizova OA, Dumikyan ASh, Shvachko AG, Sergienko VI, Syrkin AL. [Oxidative modification of fibrinogen in patients with coronary heart disease]. Rossijskij Kardiologicheskij Zhurnal. 2015;1:24. [Article in Russian]. 9. Fomina MA, Abalenihina YuV. Oxidative modification of tissue proteins with a change in the synthesis of nitric oxide. M: Gehotar-Media; 2018. [In Russian].

10. Wick G, Knoflach $\mathrm{M}, \mathrm{Xu}$ Q. Autoimmune and inflammatory mechanisms in atherosclerosis. Annu Rev Immunol. 2017;22:361-403.

11. Trott A, West JD, Klaić L, Westerheide SD, Silverman RB, Morimoto RI, Morano KA. Activation of heat shock and antioxidant responses by the natural product celastrol: transcriptional signatures of a thiol-targeted molecule. Mol Biol Cell. 2008;19(3):1104-12. doi: 10.1091/mbc.E07-10-1004.

12. Wu CW, Biggar KK, Zhang J, Tessier SN, Pifferi F, Perret M, Storey KB. Induction of Antioxidant and Heat Shock Protein Responses During Torpor in the Gray Mouse Lemur, Microcebus murinus. Genomics Proteomics Bioinformatics. 2015;13(2):119-26. doi: 10.1016/j.gpb.2015.03.004.

13. Juonala M, Viikari JS, Laitinen T, Marniemi J, Helenius H, Rönnemaa T, Raitakari OT. Interrelations between brachial endothelial function and carotid intima-media thickness in young adults: the cardiovascular risk in young Finns study. Circulation. 2004;110(18):2918-23.

14. Davydchyk EV, Snezhitskiy VA, Nikonova LV. [Relationship of hyperhomocysteinemia with coronary heart disease and diabetes mellitus]. Journal of the Grodno State Medical University. 2015; (1):9-13.[Article in Russian].

15. Guthikonda S, Haynes WG. Homocysteine: role and implications in atherosclerosis. Curr Atheroscler Rep. 2006;8(2):100-6.

16. Gensini GG. A more meaningful scoring system for determining the severity of coronary heart disease. Am J Cardiol. 1983;51(3):606.

17. Dubinina EE, Burmistrov SO, Khodov DA, Porotov IG. [Oxidative modification of human serum proteins. A method of determining it].Vopr Med Khim. 1995;41(1):24-6. [Article in Russian].

18. Vichova T1, Motovska Z. Oxidative stress: Predictive marker for coronary artery disease. Exp Clin Cardiol. 2013 Spring;18(2):e88-91.

19. Huo Y, Wu X, Ding J, Geng Y, Qiao W, Ge A, et al. Vascular Remodeling, Oxidative Stress, and Disrupted PPAR $\gamma$ Expression in Rats of Long-Term Hyperhomocysteinemia with Metabolic Disturbance. PPAR Res. 2018;2018:6738703. doi: 10.1155/2018/6738703.

20. Tyagi N, Qipshidze N, Sen U, Rodriguez W, Ovechkin A, Tyagi SC. Cystathionine beta synthase gene dose dependent vascular remodeling in murine model of hyperhomocysteinemia. Int J Physiol Pathophysiol Pharmacol. 2011;3(3):210-22.

21. McCully KS. Homocysteine Metabolism, Atherosclerosis, and Diseases of Aging. Compr Physiol. 2015;6(1):471-505. doi: $10.1002 /$ cphy.c150021.

22. Giles WH, Croft JB, Greenlund KJ, Ford ES, Kittner SJ. Total homocyst(e)ine concentration and the likelihood of nonfatal stroke: results from the Third National Health and Nutrition Examination Survey, 1988-1994. Stroke. 1998;29(12):2473-7. 23. McCully KS. Vascular pathology of homocysteinemia: implications for the pathogenesis of arteriosclerosis. Am J Pathol. 1969;56(1):111-28.

24. Kanwar YS, Manaligod JR, Wong PW. Morphologic 
studies in a patient with homocystinuria due to 5, 10-methylenetetrahydrofolate reductase deficiency. Pediatr Res. 1976;10(6):598-609.

25. Bostom AG, Silbershatz H, Rosenberg IH, Selhub J, D'Agostino RB, Wolf PA, et al. Nonfasting plasma total homocysteine levels and all-cause and cardiovascular disease mortality in elderly Framingham men and women. Arch Intern Med. 1999;159(10):1077-80.

26. Ren J, Liu C, Zhao D, Fu J. The role of heat shock protein 70 in oxidant stress and inflammatory injury in quail spleen induced by cold stress. Environ Sci Pollut Res Int. 2018 Jul;25(21):21011-21023. doi: 10.1007/s11356-018-2142-8. 27. Zhu J, Quyyumi AA, Wu H, Csako G, Rott D, ZallesGanley A, et al. Increased serum levels of heat shock protein 70 are associated with low risk of coronary artery disease. Arterioscler Thromb Vasc Biol. 2003;23(6):1055-9.

28. Martin-Ventura JL, Leclercq A, Blanco-Colio LM, Egido J, Rossignol P, Meilhac O, Michel JB. Low plasma levels of HSP70 in patients with carotid atherosclerosis are associated with increased levels of proteolytic markers of neutrophil activation. Atherosclerosis. 2007;194(2):334-41.

29. Wright BH, Corton JM, El-Nahas AM, Wood RF, Pockley

AG. Elevated levels of circulating heat shock protein 70 (Hsp70) in peripheral and renal vascular disease. Heart Vessels. 2000;15(1):18-22.

30. Xie F, Zhan R, Yan LC, Gong JB, Zhao Y, Ma J, Qian LJ. Diet-induced elevation of circulating HSP70 may trigger cell adhesion and promote the development of atherosclerosis in rats. Cell Stress Chaperones. 2016;21(5):907-14. doi: 10.1007/s12192-016-0716-2.

31. Rodríguez-Iturbe B, Johnson RJ. Heat shock proteins and cardiovascular disease. Physiol Int. 2018;105(1):19-37. doi: 10.1556/2060.105.2018.1.4.

32. Bielecka-Dabrowa A, Barylski M, Mikhailidis DP, Rysz J, Banach M. HSP 70 and atherosclerosis--protector or activator? Expert Opin Ther Targets. 2009;13(3):307-17. doi: $10.1517 / 14728220902725149$.

33. Pockley AG, Georgiades A, Thulin T, de Faire U, Frostegård J. Serum heat shock protein 70 levels predict the development of atherosclerosis in subjects with established hypertension. Hypertension. 2003;42(3):235-8.

34. Dulin E, García-Barreno P, Guisasola MC. Extracellular heat shock protein 70 (HSPA1A) and classical vascular risk factors in a general population. Cell Stress Chaperones. 2010;15(6):929-37. doi: 10.1007/s12192-010-0201-2.

35. Marber MS, Mestril R, Chi SH, Sayen MR, Yellon DM, Dillmann WH. Overexpression of the rat inducible $70-\mathrm{kD}$ heat stress protein in a transgenic mouse increases the resistance of the heart to ischemic injury. J Clin Invest. 1995;95(4):1446-56. 36. Plumier JC, Ross BM, Currie RW, Angelidis CE, Kazlaris H, Kollias G, Pagoulatos GN. Transgenic mice expressing the human heat shock protein 70 have improved post-ischemic myocardial recovery. J Clin Invest. 1995;95(4):1854-60.

37. Radford NB, Fina M, Benjamin IJ, Moreadith RW, Graves $\mathrm{KH}$, Zhao P, et al. Cardioprotective effects of $70-\mathrm{kDa}$ heat shock protein in transgenic mice. Proc Natl Acad Sci U S A. 1996;93(6):2339-42.

38. Trost SU, Omens JH, Karlon WJ, Meyer M, Mestril R, Covell JW, Dillmann WH. Protection against myocardial dysfunction after a brief ischemic period in transgenic mice expressing inducible heat shock protein 70 . J Clin Invest. 1998;101(4):855-62. 